\title{
Development of a Polymerase Chain Reaction-Temporal Temperature Gradient Gel Electrophoresis Assay for Identification of Salmonella enterica Subspecies enterica Using a Hypothetical Non-specific Endonucleas S. entericae Gene Sequence
}

\author{
Maryam Besharati, ${ }^{1,2,3}$ Ahmad Reza Bahrami, ${ }^{1,2,}$ Mansour Mashreghi,, ${ }^{1,4}$ Maryam Matin,,2 and Monireh \\ Bahrami $^{1,2}$ \\ ${ }^{1}$ Department of Biology, Faculty of Science, Ferdowsi University of Mashhad, Mashhad, IR Iran \\ ${ }^{2}$ Cell and Molecular Biotechnology Research Group, Institute of Biotechnology, Ferdowsi University of Mashhad, Mashhad, IR Iran \\ ${ }^{3}$ Department of Microbial Biotechnology, Microbial Technology and Products Research Center, College of Science, University of Tehran, Tehran 14155-6455, IR Iran \\ ${ }^{4}$ Center of Nano Research, Ferdowsi University of Mashhad, Mashhad, Iran \\ "Corresponding author: Ahmad Reza Bahrami, Ferdowsi University of Mashhad (FUM) campus, Azadi Sq., Mashhad, Khorasan Razavi, Iran. Tel: +98-9155164297, Fax: \\ +98-5118762227, E-mail: ar-bahrami@um.ac.ir
}

Received 2016 September 02; Revised 2016 December 15; Accepted 2017 January 24.

\begin{abstract}
Background: Salmonella is one of the major agents of food-borne diseases that cause severe illness in humans. The conventional detection methods of these bacteria are time-consuming with low sensitivity and specificity, which limit their applications. Therefore, developing more rapid and accurate methods is urgently required in food safety programs.

objectives: In this study for the first time, polymerase chain reaction-Temporal temperature gradient gel electrophoresis (TTGE) was optimized for the identification of Salmonella enterica subspecies enterica serovars in processed food samples using a single-copy sequence.

Methods: DNA was isolated from pure cultures of Salmonella and non-Salmonella strains. The single copy target sequence was selected and amplified by employing the polymerase chain reaction (PCR) with specific primers, designed in this study, and their specificity and sensitivity were determined. The TTGE parameters, especially the temperature gradient and the time of reaction, were optimized and then this method was applied to investigate spiked food samples.

Results: The PCR detection sensitivity was recorded as $12 \times 10^{3} \mathrm{CFU} / \mathrm{mL}$ in artificially-contaminated food samples. The best resolution was observed at a temperature gradient from 62.5 to $67.5^{\circ} \mathrm{C}$, with a ramp rate of $1^{\circ} \mathrm{C} /$ hour and electrophoresis for 5 hours at a constant voltage of $130 \mathrm{~V}$. The TTGE patterns obtained from the artificially-contaminated samples were similar with the respected standard bacteria strains. The optimized TTGE protocol resulted in the separation of the same length PCR products into different band positions on the polyacrylamide gel.

Conclusions: By optimization of PCR-TTGE and determination of distinct band pattern for standard bacteria, this method can be used as a fast screening test to investigate the presence of S. enterica, subspecies enterica, directly in food samples.
\end{abstract}

Keywords: Polymerase Chain Reaction, Temporal Temperature Gradient gel Electrophoresis, Salmonella enterica, Food Sample

\section{Background}

Salmonella is one of the most common pathogens of food-borne disease with an estimated 93.8 million human infections and 155,000 deaths annually worldwide (1). The genus Salmonella is a Gram-negative, rod-shaped, facultative anaerobe belonging to the Enterobacteriaceae family. This genus is divided to two species, S. enterica and S. bongori. Salmonella enterica includes over 2500 serovars (2). Consumption of contaminated food, especially animal origins, causes most Salmonella infections. In order to ensure food safety, it is necessary to control Salmonella presence in all key stages of food production process (3). Tra- ditional methods for detection of Salmonella require preenrichment, selective enrichment as well as isolation on selective agar, which can then be characterized by performing additional biochemical and/or serological tests. Standard culture methods are excessively time consuming ( 7 to 5 days) and labor intensive (4). Another problem is the lack of knowledge of the actual condition for bacterial growth in their natural resources.

Currently, investigations of Salmonella typing are performed by serotyping, according to the Kauffmann-White scheme (5). Serotyping has limitations in its use, antiserum production, quality test variation, and high cost. In addition, serological tests are usually undertaken at refer- 
ence laboratories and have been rarely performed in routine food or clinical laboratories. Consequently, nucleic acid-based approaches for Salmonella spp. detection have been popularized based on DNA or RNA polymorphism. These methods offer advantages of sensitivity, specificity, and reproducibility over other methods, rapidly identifying Salmonella without obtaining pure cultures (6). The polymerase chain reaction (PCR) is a major technique of the assays.

Polymerase chain reaction-temporal temperature gradient gel electrophoresis (TTGE) is a PCR-denaturing gradient gel electrophoresis that allows separation of DNA fragments of the same length, yet, with different sequences in a temporal gradient of temperature, simultaneously (7). Most of the studies, done so far, for identification of Salmonella by PCR-denaturing gradient gel electrophoresis (DGGE) are based on $16 \mathrm{~S}$ and $23 \mathrm{~S}$ ribosomal DNA sequences $(8,9)$. The nature of multiple copies of these sequences has limitations such as determination of the banding profile of target microorganisms prior to TTGE or DGGE assay.

To distinguish the species of S. enterica subspecies enterica by the TTGE method, the bacteria-specific primers (designed in this study), targeting a sequence for a hypothetical non-specific endonuclease, were used. The sequence was single-copy and has been shown to have some degree of polymorphism among these bacteria. Using this method, different bacteria strains in food samples were detectable with high accuracy.

\section{Objectives}

In the present study, the ability of a specific single-copy sequence and TTGE technique to distinguish different bacteria belonging to $S$. enterica subspecies enterica in food (chicken sausage) was assayed.

\section{Methods}

\subsection{Bacterial strains and Culture Condition}

The Salmonella and the non-Salmonella bacterial strains used in this study are listed in Table 1. They were cultured on non-selective Tryptic soy broth (TSB) under aerobic conditions at $37^{\circ} \mathrm{C}$ for 24 hours.

\subsection{Rapid DNA Extraction and PCR Assay Design}

Extraction of DNA was performed from pure cultures by the boiling method as follows (10): Aliquots of $1 \mathrm{~mL}$ of bacterial suspensions were centrifuged at $15000 \mathrm{~g}$ for 3 minutes. The pellet was resuspended in $500 \mu \mathrm{L}$ of sterile deionized distilled water and vortex agitated. The suspensions were heated at $100^{\circ} \mathrm{C}$ for 10 minutes, immediately
Table 1. Salmonella and non-Salmonella Strains Used in This Study

\begin{tabular}{lc}
\hline Salmonella Strains & Non-Salmonella Bacteria Strains \\
\hline $\begin{array}{l}\text { Salmonella typhimurium (ATCC: } \\
\text { 14028) }\end{array}$ & Escherichia coli (ATCC: 25922) \\
\hline Salmonella typhi (PTCC: 1609) & Klebsiella pneumoniae (ATCC: 700603) \\
\hline $\begin{array}{l}\text { Salmonella paratyphi B (NCTC: } \\
\text { 8390) }\end{array}$ & Proteus mirabilis (clinical isolate) \\
Salmonella dublin (animal isolate) & Citrobacter freundii (clinical isolate) \\
\hline
\end{tabular}

cooled on ice for 10 minutes and followed by centrifugation at 15,000 $\mathrm{g}$ for 3 minutes. The supernatant, containing DNA, was kept for use in the PCR reaction. In addition, the DNA was extracted from food samples (chicken sausage purchased from the market) and inoculated with standard Salmonella strains by the BIONEER DNA extraction kit, according to the manufacturer's protocol (BIONEER Corporation, Korea).

The 254-bp fragment was amplified using the newly designed primers salF and salR. For PCR-TTGE a 40-bp GC rich fragment, the 'GC clamp, was added for the 5' end of the reverse primer salR. The primers were designed by the AlleleID software (version 6). Sequences of primers are shown in Table 2. The final volume of the reaction mixture was $20 \mu$ L containing $1 \mu \mathrm{L}$ of each primer (10 pM each), $0.4 \mu \mathrm{L}$ of dNTPs (10 mM), $0.5 \mu \mathrm{L}_{\text {of }} \mathrm{MgCl}_{2}(50 \mathrm{mM}), 2 \mu \mathrm{L}$ of $10 \mathrm{X}$ reaction buffer, $0.2 \mu \mathrm{L}$ of Taq DNA polymerase $(50 \mathrm{u} /$ $\mu \mathrm{L}$ ), and $2 \mu \mathrm{L}$ of template DNA. The amplification was conducted in a thermocycler (Corbett) and the program was as follows: $94^{\circ} \mathrm{C}$ for 5 minutes, 35 cycles of 20 seconds at $94^{\circ} \mathrm{C}, 30$ seconds at $62^{\circ} \mathrm{C}$, and 30 seconds at $72^{\circ} \mathrm{C}$, followed by 7 minutes at $72^{\circ} \mathrm{C}$. The PCR products were examined by electrophoresis on a $1.2 \%$ agarose gel, followed by staining with ethidium bromide and viewing under Ultraviolet light (UV) before TTGE migration.

Table 2. Primers Used for the Amplification of the Hypothetical Non-Specific Endonuclease Gene in the Salmonella Genus

\begin{tabular}{lc}
\hline Primer & Prime Sequence \\
\hline salF & 5'-CGCTTCTCATCGGCAACC -3' \\
salR & 5'-CGCCCGCCGCGCCCCGCGCCCGTCCCGCCGCCCC \\
& CGCCCGGTCAAAAAGTGAAGGAAATTACGC -3 ${ }^{\text {,a }}$ \\
\hline $\begin{array}{l}\text { a The underlined sequence in salR indicates the GC clamp required for TTGE } \\
\text { analysis. }\end{array}$
\end{tabular}

\subsection{Selectivity and Sensitivity of Primers}

The selectivity of the designed salF and salR primers were determined using DNA purified from non-Salmonella strains belonging to the Enterobacteriaceae family (Table 1). 
The PCR sensitivity was determined using an enriched overnight culture of S. typhimurium. A serial of 10-fold dilutions was prepared in sterile distilled water to obtain suspensions containing 100 to 108 Colony Forming Units (CFU) of S. typhimurium per milliliter. The bacterial concentrations were estimated by absorbance readings and comparison with the McFarland table. A 25-g of sliced sterile food sample (autoclaved chicken sausage sample) was transferred into $225 \mathrm{~mL}$ of buffered peptone water (BPW) and homogenized for 5 minutes with a homogenizer instrument (Heidolph homogenizer, DIAX 900) and inoculated with $1 \mathrm{~mL}$ of an overnight culture of S. typhimurium (12 $\times 10^{8} \mathrm{CFU} / \mathrm{mL}$ ) (11). A 1-mL aliquot was removed and transformed into a tube containing a $9 \mathrm{~mL}$ of sterile BPW. This action was continued to obtain a serial of 10 -fold dilutions. A negative control of uninoculated sterile food sample was also included.

\subsection{Temporal Temperature Gradient Gel Electrophoresis Analy- sis}

After PCR, the amplicons were subsequently applied to TTGE analysis. The TGGE was performed on DCode universal mutation detection system (Bio-Rad, USA) by running on $8 \%$ acrylamide gel $(160 \times 160 \times 1 \mathrm{~mm})$ containing $6 \mathrm{M}$ urea in $1 \mathrm{X}$ TAE buffer. The TTGE conditions such as temperature range, voltage, and time were optimized. Prior to the experiment, the initial and final temperatures were determined theoretically using the WinMelt ${ }^{\mathrm{TM}}$ software (BioRad, USA). Finally, the electrophoresis was conducted with a constant voltage of $130 \mathrm{~V}$, a temperature gradient from 62.5 to 67.5 and ramping rate of $1^{\circ} \mathrm{C} / \mathrm{h}$ for 5 hours. A TTGE diversity ladder was generated by mixing the PCR products of the standard bacteria strains. After electrophoresis, DNA band patterns related to the standard strains and spiked food samples were observed with silver staining.

\section{Results}

Using the newly designed primers specific to S. enterica subspecies enterica, the PCR produced a sharp band of the expected 254 bp with all the examined Salmonella strains under optimal condition (Figure 1).

In order to examine the specificity of the newlydesigned primers among the several genera of the family Enterobacteriaceae, some non-Salmonella strains were tested by the PCR assay. After optimizing the PCR conditions and reagent concentrations, at an annealing temperature of $62^{\circ} \mathrm{C}$ and $1.25 \mathrm{mM} \mathrm{MgCl}_{2}$, PCR analysis of nonSalmonella strains showed no detectable bands (Figure 2).

To determine the limits of detection (LOD) and sensitivity of the PCR assay, the standard strain of S. typhimurium

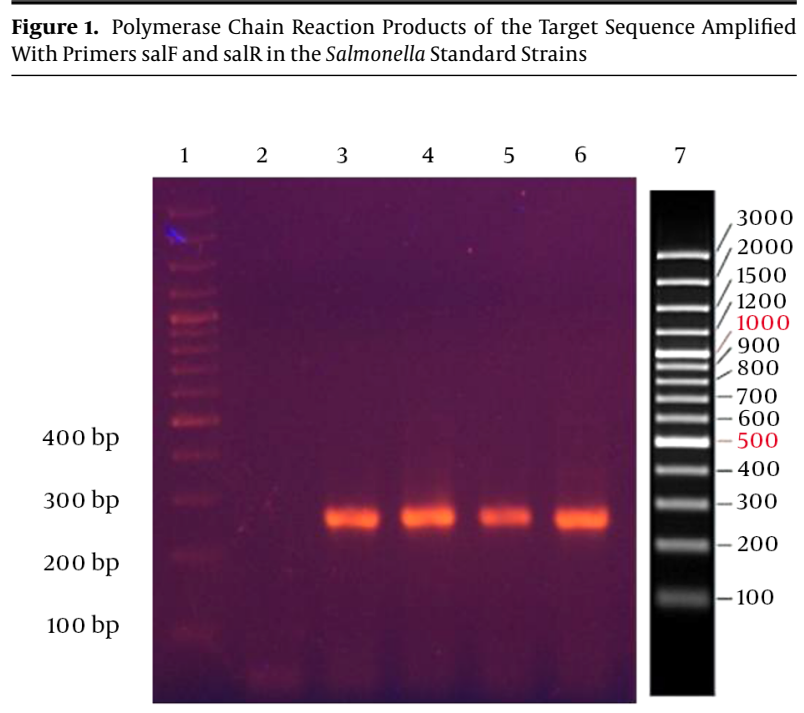

Each lane represents:1) 100 bp DNA ladder, 2) negative control, 3) S. typhimurium, 4) S. typhi, 5) S. paratyphi B, 6) S. dublin, and 7) schematic ladder.

Figure 2. Polymerase Chain Reaction Products of the Target Sequence Amplified With Primers salF and salR in the Salmonella and non-Salmonella Strains

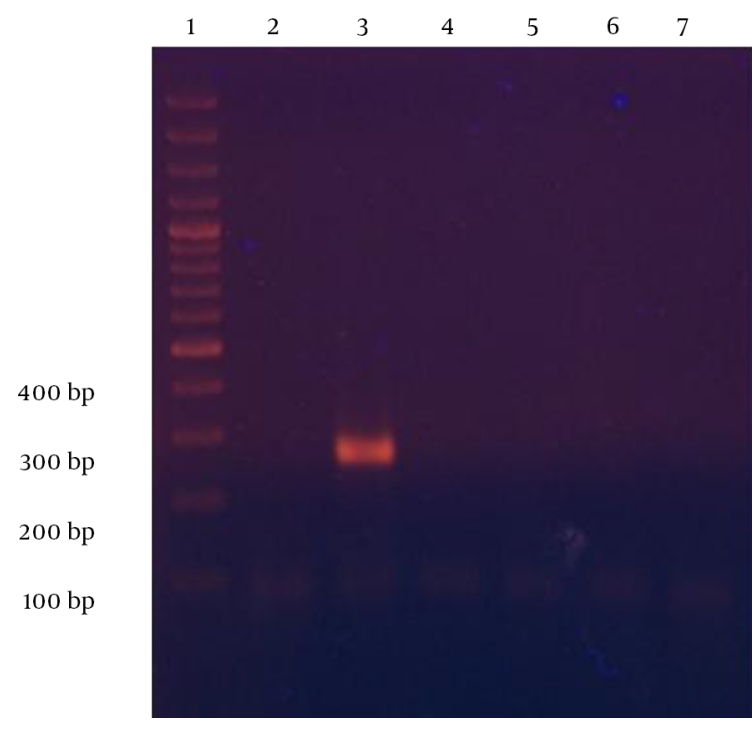

Each lane represents: 1) 100 bp DNA ladder, 2) negative control, 3) S. typhimurium, 4) E. Coli, 5) Proteus mirabilis, 6) Klebsiella pneumoniae, and 7) Citrobacter freundii.

was serially diluted in sterile distilled water. The dilutions were used directly for DNA extraction by the boiling method. In addition, serial dilutions of the spiked chicken sausage were used for DNA extraction by the BIONEER DNA extraction kit, according to the manufacturer's protocol. The detection limits were established by examination on 
the lowest dilution of the extracted DNA. The LOD of the PCR assay was found to be $12 \times 10^{5} \mathrm{CFU} / \mathrm{mL}$ for the standard strain and $12 \times 10^{4} \mathrm{CFU} / \mathrm{mL}$ for the spiked food sample. Also, a faint band was observed at $10^{3} \mathrm{CFU} / \mathrm{mL}$ (Figures 3 and 4 ).

Figure 3. Polymerase Chain Reaction Products of the Target Sequence Amplified With Primers salF and salR for Determination of Limit of Detection in the Standard Strain Salmonella typhimurium

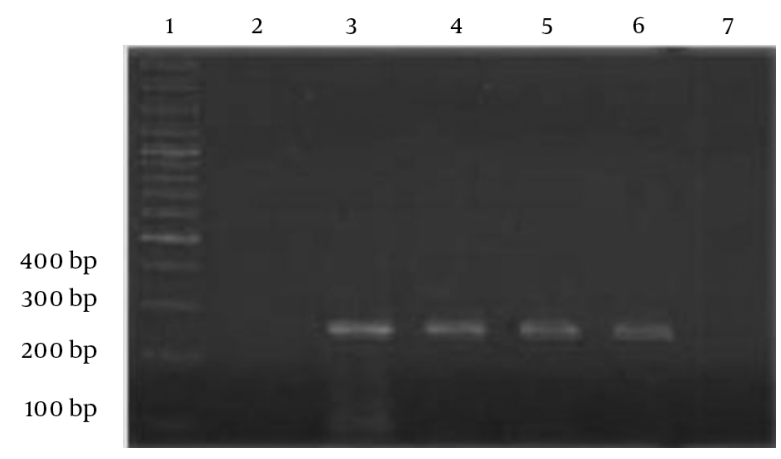

Each lane represents: 1) 100 bp DNA Ladder, 2) negative control, and 3, 4, 5, 6 and 7) dilutions of $12 \times 10^{8} \mathrm{CFU} / \mathrm{mL}$ to $\mathrm{CFU} / \mathrm{mL} 12 \times 10^{4}$, respectively.

Figure 4. Polymerase Chain Reaction Products of the Target Sequence Amplified With Primers salF and salR for Determination of the Limit of Detection in the Spiked Food Sample

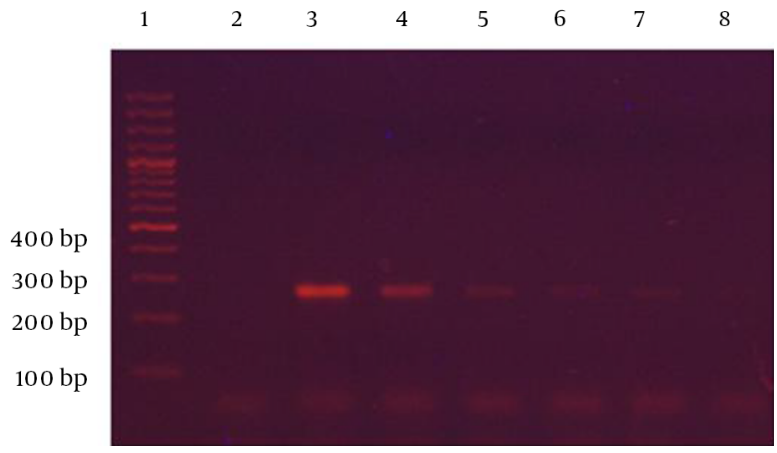

Each lane represents: 1) 100 bp DNA ladder, 2) negative control, and 3, 4, 5, 6, 7, 8) dilutions of $12 \times 10^{8} \mathrm{CFU} / \mathrm{mL}$ to $12 \times 10^{3} \mathrm{CFU} / \mathrm{mL}$, respectively.

After designing the specific primers and ensuring their performance in the PCR assay, the products of the standard strains and the spiked food samples, were subjected to the TTGE analysis. The sequence difference in target sequences of the examined bacteria was 2 to 8 nucleotides. It was shown that DNA from all Salmonella strains, tested in this research, migrated to different distances and successfully differentiated under optimized conditions. The TGGE analysis of DNA from spiked food samples resulted in unique band positions and migrated the equivalent distances with the Salmonella standard strains, suggesting the high reproducibility and accuracy in the identification of Salmonella strains in food matrices (Figure 5). The molecular ladder is also detectable in Figure 5.

Figure 5. Temporal Temperature Gradient gel Electrophoresis Band Separation Patterns of Polymerase Chain Reaction Products of the Target Sequence Amplified With Primers salF and salR in Salmonella Standard Strains and Spiked Food Samples

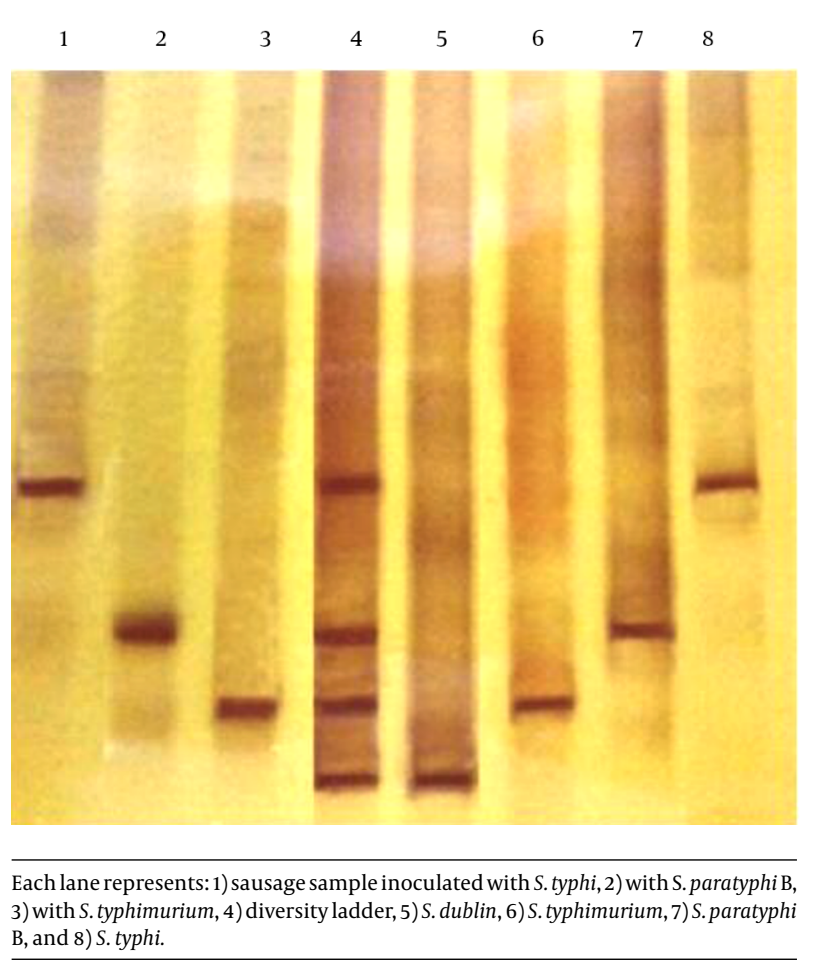

\section{Discussion}

Salmonella is one of the major agents of food-borne diseases, which causes severe illness in humans. It is estimated that the infections due to Salmonella cause 1.4 million cases annually and result in economic losses between 500 million to 2.3 billion dollars in the US $(12,13)$. Poultry products can be the main source of human diseases caused by the pathogenic bacteria of Salmonella (14). Polymerase chain reaction has been reported widely for detection of Salmonella spp. and various pathogens. Meanwhile, the application of this method in the area of food testing compared to the clinical laboratories is limited (15).

In the recent years, culture-independent methods of PCR-DGGE and PCR-TTGE are used in evaluation and dynamic displaying of the microbial population of fermented foods such as silica cheese and Italian fermented 
sausages, and cassava fermented paste has provided a rapid and reliable data (16). Denaturing gradient gel electrophoresis is a widely used method for genetic fingerprinting of the microbial population (17). This method makes isolation of complex microbial population possible, through the separation and immigration intervals of PCR amplicons, which were different even in one nucleotide in the sequence $(7,17)$. While the DGGE method is often used to evaluate the population in the taxonomy level of genus (or higher), some evaluations in species level have also been done (18).

No research has been conducted for the identification of Salmonella bacteria with TTGE and DGGE methods using a single copy target sequence. In a study by Anderson et al. in 2010, they evaluated the isolation of different Salmonella serotypes by PCR-DGGE (8). Although this method was successful in separating the PCR products of serotypes, it needs to culture, identify, and isolate the bacteria before the PCR-TTGE test, due to using a spacer region located between the 16S and 23S rDNA genes as the target. Due to the nature of this target sequence with multiple copies, determination of special banding profile of each bacterium is essential. Thus, it is not a culture-independent method any longer. Also, the time duration of the DGGE method was 17 hours, which is very long in comparison to the TTGE method optimized in this study ( $5 \mathrm{~h})$.

The selected single-copy sequence in this study for identification of the subspecies of $S$. enterica using TTGE method was evaluated by Aabo et al. in 1993 and the variation of this sequence between different serotypes of S. enterica (interserovar sequence diversity) was reported (19), while, the mentioned sequence was introduced as an unknown sequence. According to the conducted evaluations in the present study, this sequence was determined as a non-specific endonuclease gene.

To confirm the specificity of the designed primers, salF and salR, the other bacteria that belonged to the Entrobacteriaceae family, which have a high affinity with S. enterica, were tested. After consecutive experiments and optimization of PCR conditions, especially the annealing temperature and $\mathrm{MgCl}_{2}$ concentration, no non-specific band in relation to this bacteria was observed, confirming the specificity of the selected primers.

The optimized TTGE method in this study was able to separate the PCR products, with very low number of nucleotide differences, obtained from the amplification of the target sequence in the intended bacteria successfully. The sequences were different only in 2 to 8 , in terms of nucleotide content. The same patterns of the electrophoretic bands were produced on PCR products of the inoculated food, making it a suitable choice for identification of the same bacteria in the food industry.
Several studies, including multiplex PCR and real-time multiplex PCR, have been conducted to identify some serotypes of $S$. enterica, simultaneously $(10,20,21)$. Multiplex tests identify only a limited number of species in each reaction. Despite the advantage of real-time PCR by providing both qualitative and quantitative results without the need for electrophoresis, the common limitation of multiplex real-time PCR in routine food tests, is its high cost in terms of both devices and materials. Also, the numbers of species, which can simultaneously be detected by this method, are limited because of the low number of fluorophore varieties.

An advantage of the TTGE method is that it can evaluate microbial population in a single test, simultaneously, using one pair of primers. This could reduce the cost and the time of the test. This study indicated the very high sensitivity of the test in detecting the nucleotide differences among sequences, suggesting the entire process as a good method for rapid screening of food-born Salmonella species; Roudiere et al. in 2009 also isolated 53 different bacterial species from feces samples of infants with optimized TTGE conditions (22). This technique is also efficient for the detection of microorganisms, which are only $1 \%$ of the population, and there is no need to prepare the denaturant gradient of the chemicals, compared to DGGE. This makes it an easy and user-friendly method (23).

In general, TTGE has the advantages of simultaneous isolation of several serotypes in one experiment, without the use of several primers for amplification of different target sequences. However, TTGE has limitations such as DNA extraction and amplification reaction. Also, only small fragments, up to 500 basepairs, can be analyzed with this method. This limits the amount of sequence information for phylogenetic studies. Furthermore, achieving a good resolution for the analysis of mixed bacterial populations is a problem (24).

The optimized and more specific results of the PCRTTGE obtained in this study, proved this method as an appropriate method to detect bacteria belonging to species S. enterica, subspecies enterica in the inoculated food samples. However, for development of an efficient method for direct detection of bacteria in natural food samples and/or environmental or hospital samples, more research is required.

\section{Acknowledgments}

This work was supported by Ferdowsi University of Mashhad. 


\section{Footnotes}

Conflict of Interest: The authors declare no conflict of interest.

Funding/Support: This work was supported by a grant from Ferdowsi University of Mashhad (No. 3/22699).

\section{References}

1. Hendriksen RS, Vieira AR, Karlsmose S, Lo Fo Wong DMA, Jensen AB, Wegener HC, et al. Global Monitoring ofSalmonellaSerovar Distribution from the World Health Organization Global Foodborne Infections Network Country Data Bank: Results of Quality Assured Laboratories from 2001 to 2007. Foodborne Pathogens Dis. 2011;8(8):887-900. doi: 10.1089/fpd.2010.0787.

2. Barrow PA, Methner U. Salmonella in domestic animals. CABI; 2013.

3. Dhama K, Rajagunalan S, Chakraborty S, Verma AK, Kumar A, Tiwari $\mathrm{R}$, et al. Food-borne pathogens of animal origin-diagnosis, prevention, control and their zoonotic significance: a review. PakJ Biol Sci. 2013;16(20):1076-85. [PubMed: 24506006].

4. Schonenbrucher V, Mallinson ET, Bulte M. A comparison of standard cultural methods for the detection of foodborne Salmonella species including three new chromogenic plating media. Int J Food Microbiol. 2008;123(1-2):61-6. doi: 10.1016/j.ijfoodmicro.2007.11.064. [PubMed: 18192050].

5. Wattiau P, Boland C, Bertrand S. Methodologies for Salmonella enterica subsp. enterica subtyping: gold standards and alternatives. Appl Environ Microbiol. 2011;77(22):7877-85. doi: 10.1128/AEM.05527-11. [PubMed: 21856826].

6. Lee KM, Runyon M, Herrman TJ, Phillips R, Hsieh J. Review of Salmonella detection and identification methods: Aspects of rapid emergency response and food safety. Food Control. 2015;47:264-76. doi:10.1016/j.foodcont.2014.07.011.

7. Myers RM, Fischer SG, Lerman LS, Maniatis T. Nearly all single base substitutions in DNA fragments joined to a GC-clamp can be detected by denaturing gradient gel electrophoresis. Nucleic Acids Res. 1985;13(9):3131-45. [PubMed: 4000972].

8. Anderson PN, Hume ME, Byrd JA, Hernandez C, Stevens SM, Stringfellow $\mathrm{K}$, et al. Evaluation of repetitive extragenic palindromicpolymerase chain reaction and denatured gradient gel electrophoresis in identifying Salmonella serotypes isolated from processed turkeys. Poult Sci. 2010;89(6):1293-300. doi: 10.3382/ps.2009-00390. [PubMed: 20460676]

9. Maciel BM, Marques EL, Dias JC, Santos TF, Romano CC, Brendel M, et al. Denaturing gradient gel electrophoresis analysis of $16 \mathrm{~S}$ ribosomal DNA to monitor changes in mouse gut bacterial communities during Salmonella enterica serovar Enteritidis latent infection. Genet Mol Res. 2013;12(3):2611-7. doi: 10.4238/2013.March.13.10. [PubMed: 23546981].

10. Pui CF, Wong WC, Chai LC, Lee HY, Noorlis A, Zainazor TC, et al. Multiplex PCR for the concurrent detection and differentiation of Salmonella spp., Salmonella Typhi and Salmonella Typhimurium. Trop Med Health. 2011;39(1):9-15. doi: 10.2149/tmh.2010-20. [PubMed: 22028607].
11. Silva DSP, Canato T, Magnani M, Alves J, Hirooka EY, de Oliveira TCRM Multiplex PCR for the simultaneous detection of Salmonella spp. and Salmonella Enteritidis in food. Int J Food Sci Technol. 2011;46(7):1502-7. doi:10.1111/j.1365-2621.2011.02646.x.

12. Miller M A, Sentz J, Rabaa M A, Mintz ED. Global epidemiology of infections due to Shigella, Salmonella serotype Typhi, and enterotoxigenic Escherichia coli. Epidemiol Infect. 2008;136(04) doi 10.1017/s095026880800040x.

13. Pangloli P, Dje Y, Ahmed O, Doane CA, Oliver SP, Draughon FA. Seasonal incidence and molecular characterization of Salmonella from dairy cows, calves, and farm environment. Foodborne Pathog Dis. 2008;5(1):87-96. doi: 10.1089/fpd.2008.0048. [PubMed: 18260819].

14. Amavisit P, Browning GF, Lightfoot D, Church S, Anderson GA, Whithear KG, et al. Rapid PCR detection of Salmonella in horse faecal samples. Vet Microbiol. 2001;79(1):63-74. [PubMed: 11230929].

15. McKillip JL, Drake M. Real-time nucleic acid-based detection methods for pathogenic bacteria in food. J Food Prot. 2004;67(4):823-32. [PubMed: 15083739].

16. Ercolini D. PCR-DGGE fingerprinting: novel strategies for detection of microbes in food. J Microbiol Methods. 2004;56(3):297-314. doi: 10.1016/j.mimet.2003.11.006. [PubMed:14967221].

17. Muyzer G. DGGE/TGGE a method for identifying genes from natural ecosystems. Curr Opin Microbiol. 1999;2(3):317-22. doi: 10.1016/S13695274(99)80055-1. [PubMed: 10383868].

18. Farnleitner AH, Kreuzinger N, Kavka GG, Grillenberger S, Rath J, Mach RL. Simultaneous detection and differentiation of Escherichia col populations from environmental freshwaters by means of sequence variations in a fragment of the beta-D-glucuronidase gene. Appl Environ Microbiol. 2000;66(4):1340-6. [PubMed: 10742209].

19. Aabo S, Rasmussen OF, Roseen L, Sørensen PD, Olsen JE. Salmonella identification by the polymerase chain reaction. Mol Cell Probes. 1993;7(3):171-8. doi:10.1006/mcpr.1993.1026.

20. Jamshidi A, Kalidari GA, Hedayati M. Isolation and Identification Of salmonellaenteritidis Andsalmonellatyphimurium from the Eggs of Retail Stores in Mashhad, Iran Using Conventional Culture Method and Multiplex Pcr Assay. J Food Safety. 2010 doi: 10.1111/j.17454565.2010.00225.x.

21. Lee SH, Jung BY, Rayamahji N, Lee HS, Jeon WJ, Choi KS, et al. A multiplex real-time PCR for differential detection and quantification of Salmonella spp., Salmonella enterica serovar Typhimurium and Enteritidis in meats. J Vet Sci. 2009;10(1):43-51. [PubMed: 19255523].

22. Roudiere L, Jacquot A, Marchandin H, Aujoulat F, Devine R, Zorgniotti I, et al. Optimized PCR-Temporal Temperature Gel Electrophoresis compared to cultivation to assess diversity of gut microbiota in neonates. J Microbiol Methods. 2009;79(2):156-65. doi: 10.1016/j.mimet.2009.08.005. [PubMed: 19686785].

23. Yoshino K, Nishigaki K, Husimi Y. Temperature sweep gel electrophoresis: a simple method to detect point mutations. Nucleic Acids Res. 1991;19(11):3153. [PubMed: 2057372].

24. Muyzer G, Smalla K. Application of denaturing gradient gel electrophoresis (DGGE) and temperature gradient gel electrophoresis (TGGE) in microbial ecology. Antonie Van Leeuwenhoek. 1998;73(1):12741. [PubMed: 9602286]. 